\title{
BMI
}

\section{Effectiveness of policy to provide breastfeeding groups (BIG) for pregnant and breastfeeding mothers in primary care: cluster randomised controlled trial}

\author{
Pat Hoddinott, senior clinical research fellow, ${ }^{1}$ Jane Britten, research fellow, ${ }^{1}$ Gordon J Prescott, senior \\ lecturer, ${ }^{2}$ David Tappin, senior clinical lecturer, ${ }^{3}$ Anne Ludbrook, professor, ${ }^{4}$ David I Godden, director ${ }^{1}$
}

${ }^{1}$ Centre for Rural Health, University of Aberdeen, Centre for Health Science, Inverness IV2 3JH ${ }^{2}$ Department of Public Health, University of Aberdeen, Aberdeen AB25 2ZD

${ }^{3}$ Paediatric Epidemiology and Community Health Unit, Section of Child Health, University of Glasgow, Royal Hospital for Sick Children, Glasgow G3 8S)

${ }^{4}$ Health Economics Research Unit, University of Aberdeen, Aberdeen Correspondence to: $P$ Hoddinott p.hoddinott@abdn.ac.uk

Cite this as: BMJ 2009;338:a3026 doi:10.1136/bmj.a3026

\section{ABSTRACT}

Objective To assess the clinical effectiveness and cost effectiveness of a policy to provide breastfeeding groups for pregnant and breastfeeding women.

Design Cluster randomised controlled trial with prospective mixed method embedded case studies to evaluate implementation processes.

Setting Primary care in Scotland.

Participants Pregnant women, breastfeeding mothers, and babies registered with 14 of 66 eligible clusters of general practices (localities) in Scotland that routinely collect breastfeeding outcome data.

Intervention Localities set up new breastfeeding groups to provide population coverage; control localities did not change group activity.

Main outcome measures Primary outcome: any breast feeding at 6-8 weeks from routinely collected data for two pre-trial years and two trial years. Secondary outcomes: any breast feeding at birth, 5-7 days, and 8-9 months; maternal satisfaction.

Results Between 1 February 2005 and 31 January 2007, 9747 birth records existed for intervention localities and 9111 for control localities. The number of breastfeeding groups increased from 10 to 27 in intervention localities, where 1310 women attended, and remained at 10 groups in control localities. No significant differences in breastfeeding outcomes were found. Any breast feeding at 6-8 weeks declined from $27 \%$ to $26 \%$ in intervention localities and increased from $29 \%$ to $30 \%$ in control localities ( $\mathrm{P}=0.08$, adjusted for pre-trial rate). Any breast feeding at 6-8 weeks increased from $38 \%$ to $39 \%$ in localities not participating in the trial. Women who attended breastfeeding groups were older $(\mathrm{P}<0.001)$ than women initiating breast feeding who did not attend and had higher income $(P=0.02)$ than women in the control localities who attended postnatal groups. The locality cost was $£ 13400$ ( $€ 14410 ; \$ 20144)$ a year.

Conclusion A policy for providing breastfeeding groups in relatively deprived areas of Scotland did not improve breastfeeding rates at 6-8 weeks. The costs of running groups would be similar to the costs of visiting women at home.
Trial registration Current Controlled Trials ISRCTN44857041.

\section{INTRODUCTION}

Evidence for short term and long term health benefits of breast feeding for mother and child is increasing. ${ }^{12}$ The World Health Organization states that optimal nutrition is exclusive breast feeding (breast milk with no other fluids) for six months and continued breast feeding for two years. ${ }^{3}$ Scotland has among the lowest breastfeeding rates in the developed world; only $44 \%$ of babies received any breast milk at 6 weeks in $2005 .{ }^{4}$

Two Cochrane reviews have summarised the evidence for interventions that increase the prevalence of breast feeding. ${ }^{56}$ Additional one to one professional or lay support increases the duration of any breast feeding up to 6 months, with a greater effect for exclusive breast feeding. ${ }^{6}$ Some randomised controlled trials of lay supporters and some professional education interventions in pregnancy have included group settings, ${ }^{67}$ but evidence is limited and the effectiveness of health service provided breastfeeding groups is unknown. Professional support interventions extending through pregnancy, birth, and after birth are more effective than interventions concentrating on a shorter period. ${ }^{8}$ Interventions that tackle health inequalities in breast feeding are particularly needed, as younger more disadvantaged women are less likely to breast feed. ${ }^{4}$ The UK National Institute for Health and Clinical Excellence endorses the WHO/UNICEF baby-friendly hospital initiative's 10 steps to successful breast feeding as a minimum standard for postnatal care $^{910}$ The 10th step is to foster the establishment of breastfeeding support groups and refer mothers to them at discharge from hospital. A randomised controlled trial of the baby-friendly hospital initiative, without step 10, increased the duration of breast feeding until 1 year in Belarus ${ }^{11}$; however, the generalisability of these findings to the United Kingdom is uncertain. ${ }^{12}$

A preliminary, non-randomised, controlled intervention study offering group based breastfeeding peer coaching, one to one breastfeeding peer coaching, or 
both significantly increased any breast feeding (exclusive or partial) at two weeks after birth by $6.8(95 \%$ confidence interval 1.2 to 12.4 ) percentage points, from $34.3 \%$ to $41.1 \% .^{13}{ }^{14}$ The intervention was not effective in one area, however, and the researchers hypothesised that relationships between health professionals could determine outcome. ${ }^{15}$ In addition, the extent to which the action research method contributed to the success of the intervention was unclear. ${ }^{16}$ That preliminary study informed the Breastfeeding in Groups (BIG) trial design.

Our aim was to evaluate the clinical effectiveness and cost effectiveness of a policy for providing breastfeeding groups for pregnant women and breastfeeding mothers. Our objectives were to compare before and after breastfeeding rates at 6-8 weeks and women's satisfaction with breastfeeding support and social support, and to measure the costs of the intervention to the health service and to parents. We chose a pragmatic cluster randomised controlled trial design to randomise primary care populations to receive a policy intervention. We used qualitative and quantitative methods to build embedded prospective case studies to investigate the amount of intervention delivered and the group characteristics and to compare group activity between intervention and control localities. Policy implementation processes and how they influenced outcomes in intervention localities will be reported separately.

\section{METHODS}

Participants

All 66 clusters of general practices (localities) that routinely collected breastfeeding data through the Child Health Surveillance Programme (CHSP) of the National Health Service (NHS) Scotland from October

\begin{tabular}{|c|c|c|c|}
\hline & $\begin{array}{l}\text { Policy to provide breastfeeding } \\
\text { groups (intervention) }\end{array}$ & $\begin{array}{l}\text { Usual care with no new breastfeeding } \\
\text { group activity (control) }\end{array}$ & $\begin{array}{l}\text { Non-participating localities collecting } \\
\text { outcome data (external control) }\end{array}$ \\
\hline 2 years pre-intervention & \multicolumn{3}{|c|}{ Measurement of breastfeeding outcomes (1 October 2002 to 30 September 2004) } \\
\hline \multicolumn{4}{|l|}{ Randomisation } \\
\hline \multicolumn{4}{|l|}{4 months preparation } \\
\hline \multicolumn{4}{|l|}{ Baseline } \\
\hline \multicolumn{4}{|l|}{2 years from baseline } \\
\hline 2 years from baseline & Measurement of $b$ & stfeeding outcomes (1 February 200 & 5 to 31 January 2007) \\
\hline
\end{tabular}

(a) Training day and information packs for each locality for $<20$ health visitors, midwives, or others likely to be involved in groups

b) Double pre-trial breastfeeding group activity, cover main populations in locality, and set up minimum of two new groups for two years

C) Run groups according to the protocol

(d) Set up and hold locality steering group meetings every 6-8 weeks for group facilitators, participants, voluntary sector, and relevant locality stakeholder representatives to reflect on policy implementation

(e) Structured telephone interviews every six months with key informants to map all breastfeeding related activity in each locality

f Health visitors distribute (months 6-24) questionnaire at routine 6-8 week baby check appointment to women who initiated breastfeeding (put baby to breast at least once after birth). Questionnaire includes maternal satisfaction with breastfeeding experience; social support; attendance at general birth related and specific breastfeeding groups, classes, or workshops in pregnancy and after birth, with free text question about experiences attending groups

g Group meeting attendance registers, diaries, and first time participant characteristics questionnaire

(h) Structured group observations $(n=17)$

(i) Qualitative interviews ( $n=105$ participants in 126 interviews). Focus groups $(n=13)$ with health professionals and peer supporters Individual or pair interviews (face to face $(n=41)$ or telephone $(n=27)$ ) with group facilitators, minimally involved health professionals, nurse managers, women group attenders, and non-attenders

j Questionnaire to breastfeeding group (intervention) and postnatal group (control) participants to determine costs including travel, childcare, time, and lost income, and benefits and value of groups (willingness to pay questions)

k Group facilitator workload survey over one week to assess staff costs 
2002 were eligible to participate. We recruited 14 localities, and general practice membership remained unchanged throughout the trial, despite national reorganisation of primary care. The main reasons for localities not participating were lack of capacity owing to shortages of staff, skills, or funds or service reorganisation $(\mathrm{n}=16)$; low initiation of breast feeding or existing groups meeting demand $(n=16)$; and unacceptability of the control arm as they wanted to develop groups $(\mathrm{n}=12) .{ }^{17} \mathrm{We}$ used a two stage consent process: at locality manager level and for individual women attending a group for the first time. Written and verbal information was given to pregnant women and breastfeeding mothers at 28 week antenatal appointments; at subsequent contacts with midwives, health visitors, and volunteers; and through posters in clinics and community venues.

\section{Breastfeeding group policy}

\section{In localities}

\section{Amount of intervention to be achieved}

We asked each intervention locality to at least double the amount of breastfeeding group activity, set up a minimum of two new breastfeeding groups, and ensure that all main population centres had access to a breastfeeding group

\section{Resources provided}

Each locality appointed a local investigator who was a health visitor with an interest in breast feeding. Resources were provided to protect her time for one day a week for the four month set-up period and half a day a week for the two intervention years. Each locality nominated a principal investigator (no additional funding provided), who was a public health practitioner or health promotion officer, to oversee trial implementation. Midwives and health visitors facilitated groups as part of routine antenatal and postnatal care, supported by local volunteers, other interested health service staff, and students. We provided written information for women and posters

\section{Implementation of the policy}

We asked each locality to set up steering group meetings every six to eight weeks for group facilitators and for participant, voluntary sector, and relevant locality stakeholder representatives. The aim was for steering groups to capture the multidisciplinary sharing of experiences, support, and reflective practice, which was an important component of the preliminary action research study. ${ }^{13-15}$ We asked steering groups to reflect on what was working well, what was not working so well, and what could be changed within the scope of the trial protocol and to review any changes made

\section{Pre-trial training}

We offered two half day training seminars for 20 health professionals in each locality: one on group facilitation skills led by an external consultant and one on trial conduct, protocol, and data collection. We provided a written training pack and a password protected website with access to all training materials

\section{In individual breastfeeding groups}

The following six aspects of breastfeeding groups were fixed across all seven intervention localities. These characteristics were derived from the successful preliminary action research study. ${ }^{13-15}$

\section{- Weekly group meetings}

- Women only

- A health professional group facilitator must be present

- Pregnant women and breastfeeding women to be invited to attend; implicit in this is the need for health visitors and midwives to work together to recruit women to attend groups

- At least $50 \%$ of the group meeting time to be social and interactive

- A woman centred approach to group timing, content, and structure based on the women's needs

\section{Interventions}

This was a pragmatic trial, and locality staff implemented the policy largely within existing resources. Figure 1 shows a time line describing the complex intervention and associated research activity, ${ }^{18}$ and the box describes the policy. We asked each intervention locality to at least double their number of breastfeeding groups, to set up a minimum of two new groups, and to provide population coverage. Our aim was to design a policy that was reproducible for the purpose of the trial but would incorporate some features of the action research process, which was thought to contribute to the success of the preliminary study. ${ }^{13-15}$ In the preliminary study, one precisely defined, reproducible group model did not suit all areas; however, we considered six characteristics to be important and fixed these for the BIG trial (box): weekly group meetings; women only; a health professional group facilitator; pregnant women and breastfeeding women invited to attend; at least $50 \%$ of the group meeting time to be social and interactive; and a woman centred approach. The finer details of group venue, timing, continuity of facilitator(s), structure, content, ambience, refreshments, and child care arrangements were flexible and could be decided locally. Intervention localities had four months before the start of the trial to find group venues, attend training, and appoint a local investigator.

We hypothesised that several mechanisms would operate when the policy was implemented both at locality level and at breastfeeding group level. At locality level, we anticipated multidisciplinary partnership working between midwives and health visitors and involving key stakeholders such as voluntary breastfeeding organisations. At breastfeeding group level, we hypothesised that groups would improve self efficacy with breast feeding and facilitate pregnant women seeing breast feeding and sharing experiences with mothers, thus positively influencing feeding decisions. ${ }^{19-21}$ Groups would provide opportunities for additional professional and lay support. ${ }^{6}$ Support would be informational, emotional, and affirmational, ${ }^{22}$ and it would operate between individuals and groups, both within and outside the group setting, through social networking.

\section{Outcomes}

Our primary outcome was the number of babies receiving any breast milk at $6-8$ weeks. Secondary outcomes were the number of babies receiving any breast milk at birth, 5-7 days, and 8-9 months, as well as maternal satisfaction and social support. Breastfeeding outcome data came from two routinely collected national databases: CHSP data collected by health visitors at the first visit, which records feeding at birth, at discharge from hospital, and around 10 days; the 6-8 week and 8-9 month child development reviews ${ }^{23}$; and Guthrie data collected by midwives at days 5-7 for the phenylketonuria screening programme, in which the blood spot card documents the current feeding 
method.$^{24}$ Comparing Guthrie and CHSP data, with their different collection methods, enabled us to assess completeness of population coverage. For non-participating localities, we analysed CHSP and Guthrie data.

We assessed maternal satisfaction with breast feeding and social support by using the maternal breastfeeding evaluation scale and the Duke-UNC functional social support scale. ${ }^{2526}$ We gave a postal return questionnaire to a cohort of mothers who initiated breast feeding (defined as having given their baby breast milk at least once), when they attended their 6-8 week child development assessment. The questionnaire also asked about sociodemographic characteristics, feeding history, attendance at birth related groups, and their perceived helpfulness.

We collected quantitative and qualitative data (fig 1) to build case studies at two levels: the case defined as the locality (intervention and control) to investigate differences in implementation of the intervention and

\section{Table 1 |Characteristics of intervention, control, and non-participating localities}

\begin{tabular}{|c|c|c|c|}
\hline Characteristic & Intervention & Control & Non-participating \\
\hline \multicolumn{4}{|l|}{ Pre-intervention (baseline) } \\
\hline \multicolumn{4}{|l|}{$\begin{array}{l}\text { General practices classified as urban, } \\
\text { rural, remote: }\end{array}$} \\
\hline Any practice classified as four cities & 2 & 2 & NK \\
\hline $\begin{array}{l}\geq 7 \text { practices classified as "other urban } \\
\text { areas" }\end{array}$ & 3 & 2 & NK \\
\hline $\begin{array}{l}<7 \text { practices classified as "other urban } \\
\text { areas" }\end{array}$ & 2 & 3 & NK \\
\hline $\begin{array}{l}\text { No of CHSP first assessment records with } \\
\text { SIMD } 29\end{array}$ & 9332 & 8736 & 68941 \\
\hline Percentage in least deprived fifth & 17.1 & 9.9 & 20.2 \\
\hline Percentage in most deprived fifth & 25.2 & 32.1 & 25.8 \\
\hline $\begin{array}{l}\text { Median (interquartile range) maternal } \\
\text { age at time of first CHSP assessment }\end{array}$ & $29(24-33)$ & $29(23-33)$ & $30(24-34)$ \\
\hline Breastfeeding groups in January 2003 & 11 & 10 & 90 \\
\hline Breastfeeding groups at randomisation & 10 & 10 & NK \\
\hline Maternity hospital(s) within locality & 2 & 8 & NK \\
\hline $\begin{array}{l}\text { Hospital where most women delivered } \\
\text { had baby-friendly award }\end{array}$ & 3 & 4 & NK \\
\hline \multicolumn{4}{|l|}{ Post-intervention } \\
\hline $\begin{array}{l}\text { No of CHSP first assessment records with } \\
\text { SIMD }\end{array}$ & 9701 & 9060 & 71212 \\
\hline Percentage in least deprived fifth & 15.7 & 8.7 & 18.1 \\
\hline Percentage in most deprived fifth & 26.4 & 32.9 & 26.6 \\
\hline $\begin{array}{l}\text { Median (interquartile range) maternal } \\
\text { age at time of first CHSP record }\end{array}$ & $29(24-33)$ & $28(23-33)$ & $29(24-34)$ \\
\hline \multicolumn{4}{|l|}{ No of venues hosting groups: } \\
\hline Breastfeeding groups & 27 & 10 & 102 \\
\hline General antenatal groups & 11 & 11 & NK \\
\hline $\begin{array}{l}\text { Antenatal breastfeeding education } \\
\text { groups }\end{array}$ & 10 & 5 & NK \\
\hline General postnatal groups & 33 & 28 & NK \\
\hline $\begin{array}{l}\text { Hospital where most women delivered } \\
\text { had baby-friendly award }\end{array}$ & 4 & 6 & NK \\
\hline $\begin{array}{l}\text { Community breastfeeding initiatives } \\
\text { with dedicated funding* }\end{array}$ & 11 & 9 & NK \\
\hline
\end{tabular}

CHSP=Child Health Surveillance Programme; NK=not known; SMID=Scottish Index of Multiple Deprivation. *Includes peer supporter schemes; community based breastfeeding coordinators, promoters, supporters, or specialists; and "best fed" voucher scheme. in routine care between all areas and the case defined as the group to evaluate group styles and processes. In this paper, we report case study data that relate to the amount of intervention delivered and baby-friendly hospital initiative accreditation. We did a pre-trial audit of breastfeeding groups to map activity across Scotland, which we repeated at the end of the trial (table 1). Consenting first time group attenders (women and facilitators) completed a characteristics questionnaire. Their unique identifier and group content and structure were recorded in group meeting diaries. We did four structured telephone surveys with 45 key informants from 14 localities to monitor breastfeeding group activity, other breastfeeding initiatives, and changes in maternity and child health services during the intervention.

\section{Costs and benefits}

To evaluate the costs and benefits to women, we asked group facilitators to give questionnaires to all women attending breastfeeding groups (intervention) and postnatal groups (control) during three separate one week periods throughout the trial, covering different times of year, and spaced out to minimise the risk of including women more than once. The main NHS cost was staff time. NHS staff attending intervention locality groups completed work diaries over one week and recorded group and travel time in group meeting diaries.

\section{Sample size}

The minimum expected clinically important difference between breastfeeding rates at $6-8$ weeks was $6.4 \%$ over two years, which in theory would have enabled Scotland to meet its government target of $50 \%$ of women breast feeding at 6 weeks by 2005. Using 2001-2 data, we estimated a pooled standard deviation of $9.3 \%$ and correlation between pre-intervention and post-intervention rates of 0.9 . A standardised difference of $0.7(6.4 \% / 9.3 \%)$ could be detected with $80 \%$ power at the $5 \%$ level of significance with 66 units in total at one time point. By using correlated preintervention and post-intervention measurements, we needed approximately 13 localities $\left(68 \times\left(1-0.9^{2}\right)\right)$, rounded up to an even 14 in our original power calculations. The revised estimate of pooled standard deviation of $7.4 \%$ from the recruited sample indicated that we needed approximately eight localities $\left(42 \times\left(1-0.9^{2}\right)\right)$. We expected woman level secondary outcomes to have an interclass correlation coefficient of 0.01 in clusters of approximately 100 .

\section{Randomisation}

Localities varied in size, baseline breastfeeding rates, the number of pre-existing groups, and how pregnancy and postnatal care were organised. We matched them in pairs by using the three most important criteria likely to affect access to groups: mean breastfeeding rate at 6-8 weeks in 2002 and 2003; rural classification from the Scottish Household Survey, ${ }^{27}$ and existing number 
All babies born in 14 health boards in Scotland

Clusters in 10 health boards routinely collecting breast feeding data assessed for eligibility $(n=66)$

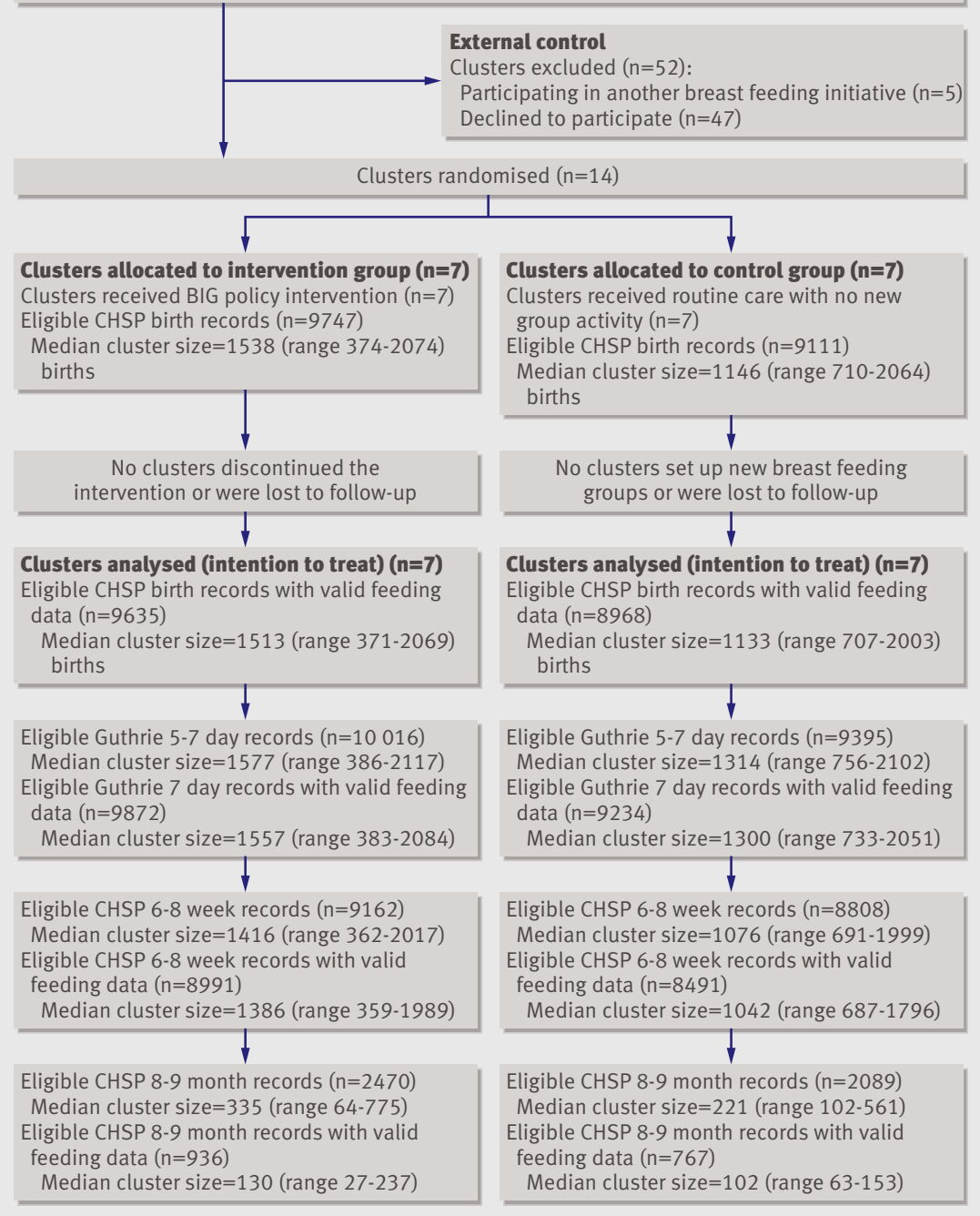

Fig 2 | Flowchart of participants. *Child Health Surveillance Programme (CHSP) 8-9 month infant feeding data ceased to be routinely collected during year 1 of the trial, with implementation of Health for all Children $4^{28}$

of breastfeeding groups per 1000 births. An independent statistician used random number tables to randomise locality pairs to either intervention or control. Researchers analysing primary and secondary outcomes were blind to allocation, ensured by coding of localities.

\section{Statistical methods}

We analysed all outcomes at cluster level on an intention to treat principle, in that we assessed the measurement of breast feeding for all locality women irrespective of attendance at a breastfeeding group. We analysed the difference in breastfeeding rates between intervention and control localities by using analysis of covariance, with pre-intervention breastfeeding rates as a covariate. By stratifying randomisation by preintervention outcome data (a strong determinant of outcome), we considered intervention and control groups to be comparable. We analysed individual level secondary outcomes by using linear or Poisson regression with adjustment for clustering. Binary variables needed logistic regression, and counts of group attendances needed zero inflated Poisson regression, both adjusted for clustering. We used either SPSS (version 15) or Stata (version 10) for analyses.

\section{RESULTS}

Figure 2 shows the flow of participants. At baseline, intervention localities had fewer general practices classified as rural, had fewer maternity units, and were slightly less deprived than control localities but were otherwise comparable (table 1). Intervention localities increased breastfeeding groups from 10 to 27 , and control localities remained unchanged with 10 groups.

\section{Feeding outcomes}

Table 2 reports the proportion of babies with valid records receiving any breast milk. The mean postintervention rates for any breast feeding at 6-8 weeks were 0.26 (SD 0.03) in intervention and $0.30(0.07)$ in control localities. After adjustment for differences in pre-intervention rates, intervention localities had postintervention rates at $6-8$ weeks 0.017 lower on average ( $95 \%$ confidence interval 0.036 lower to 0.002 higher) than control localities. This difference was not statistically significant $(\mathrm{P}=0.08)$. Any breast feeding declined in three of the seven intervention localities. We found no significant differences in rates of any breast feeding at birth, 5-7 days, or 8-9 months. Unfortunately, a change in national policy resulted in the loss of the $8-9$ month child development assessment. ${ }^{28}$ Only $25 \%$ of 8-9 month breastfeeding records (the first trial quarter) were available, and conclusions cannot be inferred. We repeated analyses for exclusive breast feeding (data not shown) and found no significant differences. The non-participating localities had higher baseline breastfeeding rates than the trial localities at all time points, but changes in breastfeeding rates were of similar size.

CHSP data enabled us to assess maternal age and deprivation at population level. ${ }^{29}$ Intervention women were three months older than controls $(\mathrm{P}<0.001)$. Table 1 reports deprivation at the first CHSP assessment (missing for $0.5 \%$ of records). Intervention women were slightly less deprived both before and after the intervention $\left(\chi^{2}\right.$ tests $\left.\mathrm{P}<0.001\right)$. We found small increases in maternal deprivation from before to after the intervention, which were statistically significant or almost significant for intervention localities $(\mathrm{P}=0.021)$, control localities $(\mathrm{P}=0.056)$, and external control localities $(\mathrm{P}<0.001)$. We assessed the completeness of primary outcome data by comparing General Register Office for Scotland (GROS) births with the number of first CHSP assessment and 6-8 week review records. In 2005, 54386 births occurred in Scotland, 46109 (84.8\%) of them in NHS boards using CHSP; 45059 first assessments (97.7\% coverage) and 43620 


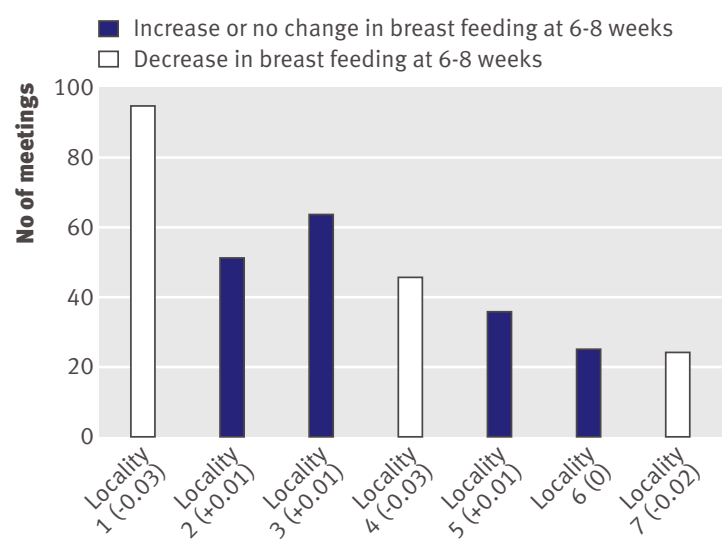

\begin{tabular}{l|l}
\hline Fig 3 & Breastfeeding group meetings per 100 locality women
\end{tabular} initiating breast feeding per year. Median=46 (interquartile range 25-64). Change in breast feeding at 6-8 weeks from two years before intervention and two intervention years shown in brackets below locality

6-8 week assessments (94.6\% coverage) took place. In 2006 , coverage was $98.1 \%$ for first assessment and $93.8 \%$ at 6-8 weeks. Comparing Guthrie records with GROS provides an estimate of $1.6 \%$ duplication of Guthrie data at 5-7 days, owing to repeat tests.

\section{Baby-friendly hospital initiative status}

Breastfeeding data by baby-friendly hospital initiative status is available on www.abdn.ac.uk/crh/big.shtml. In the seven localities where the main hospital received the award or a certificate of commitment towards the award in 2005, initiation of breast feeding increased or remained the same. For the six localities that gained the award before the pre-trial period, we found no clear pattern. These patterns were not apparent five to seven days after birth. Fewer women stopped breast feeding between birth and 5-7 days in control localities than in intervention localities before and after the intervention (table 2). The differences were of a similar order.

\section{Satisfaction and support}

We found no significant differences in maternal satisfaction or social support between intervention and control localities (table 3). Our aim for health visitors to distribute the maternal satisfaction and support questionnaire between set dates across 14 localities was challenging, particularly in control areas. Considerable change was occurring in primary care organisations at the time. ${ }^{2830}$ From intervention locality CHSP records, 3777 babies received breast milk at birth between 1 June 2005 and 30 November 2006, the intended questionnaire distribution period. Their mothers would have been eligible to receive the questionnaire at the 6-8 week assessment, and 845 $(22 \%)$ mothers completed questionnaires. In control localities, 3525 babies received breast milk at birth and $534(15 \%)$ mothers completed questionnaires. These are minimum response rates, as we know questionnaire distribution was incomplete.

\section{Group characteristics}

One of 27 breastfeeding groups did not complete group meeting diaries, and under-reporting of attendance may have occurred in larger groups (estimate 95\% complete). From 2195 group diaries, 2007 weekly group meetings took place, 188 were cancelled, and 1310 unique women (pregnant or breast feeding) attended. Median group size was four (interquartile range 2-6) women, excluding group facilitators, children, female relatives, non-pregnant friends, and students. Significantly more women in intervention than control localities knew that breastfeeding groups (antenatal and postnatal) were available and attended postnatal breastfeeding groups (data available on www. abdn.ac.uk/crh/big.shtml). Only 229/799 (28.7\%) women who initiated breast feeding reported attending antenatal breastfeeding groups in intervention localities compared with $99 / 416(23.8 \%)$ respondents in control localities $(\mathrm{P}=0.093)$. The proportions of women attending only in pregnancy, only after birth, and both

\section{Table 2|Any breast feeding (exclusive or partial) as a proportion of those with known feeding behaviour}

\begin{tabular}{|c|c|c|c|c|c|}
\hline \multirow{2}{*}{$\begin{array}{l}\text { Primary and secondary } \\
\text { outcomes }\end{array}$} & \multicolumn{2}{|c|}{ Mean (SD) breastfeeding rate } & \multirow{2}{*}{$\begin{array}{l}\text { Mean difference between groups }(95 \% \mathrm{Cl} \text { for } \\
\text { difference) }{ }^{\star}\end{array}$} & \multirow[b]{2}{*}{ Pvalue for difference* } & \multirow{2}{*}{$\begin{array}{c}\text { Non-participating } \\
\text { localities } † \text { (overall } \\
\text { proportion) }\end{array}$} \\
\hline & Intervention & Control & & & \\
\hline \multicolumn{6}{|l|}{ At $6-8$ weeks } \\
\hline Pre-intervention & $0.27(0.03)$ & $0.29(0.08)$ & & & 0.38 \\
\hline Post-intervention & $0.26(0.03)$ & $0.30(0.07)$ & $-0.017(-0.036$ to 0.002$)$ & 0.08 & 0.39 \\
\hline \multicolumn{6}{|l|}{ At birth } \\
\hline Pre-intervention & $0.50(0.05)$ & $0.51(0.10)$ & & & 0.59 \\
\hline Post-intervention & $0.51(0.06)$ & $0.53(0.09)$ & $-0.009(-0.045$ to 0.027$)$ & 0.58 & 0.60 \\
\hline \multicolumn{6}{|l|}{ At 5-7 days } \\
\hline Pre-intervention & $0.43(0.04)$ & $0.46(0.09)$ & & & 0.55 \\
\hline Post-intervention & $0.42(0.04)$ & $0.45(0.09)$ & $-0.003(-0.032$ to 0.027$)$ & 0.84 & 0.55 \\
\hline \multicolumn{6}{|l|}{ At 8-9 months } \\
\hline Pre-intervention & $0.22(0.03)$ & $0.23(0.04)$ & & & 0.28 \\
\hline Post-intervention & $0.21(0.05)$ & $0.20(0.06)$ & $0.007(-0.056$ to 0.070$)$ & 0.82 & 0.25 \\
\hline
\end{tabular}


Table 3|Maternal satisfaction and social support outcomes

\begin{tabular}{|c|c|c|c|c|c|}
\hline Scale and group & Valid responses & Missing & Interclass correlation coefficient & Median (interquartile range) & $P$ value \\
\hline \multicolumn{6}{|c|}{ Maternal breastfeeding evaluation scale ${ }^{25}$} \\
\hline Intervention & 773 & 72 & \multirow{2}{*}{$0 *$} & $118(104-130)$ & \multirow{2}{*}{$0.59 \dagger$} \\
\hline Control & 498 & 36 & & $119(105-129)$ & \\
\hline \multicolumn{6}{|c|}{ Duke-UNC functional social support scale ${ }^{26}$} \\
\hline Intervention & 822 & 23 & \multirow{2}{*}{0.003} & $4.25(3.63-4.75)$ & \multirow{2}{*}{$0.96 \ddagger$} \\
\hline Control & 517 & 17 & & $4.25(3.63-4.75)$ & \\
\hline
\end{tabular}

Higher scores represent higher perceived levels of satisfaction (maximum score 150) and social support (maximum score 5).

*Truncated to zero.

†Linear regression adjusted for clustering.

$\ddagger$ Poisson regression adjusted for clustering.

before and after birth were $0.21,0.69$, and 0.10 . From CHSP first assessment records for babies registered with locality general practitioners, each intervention locality held a median of 46 (25-64) group meetings per 100 women initiating breast feeding per year (fig 3), and a median of 23 (19-30) women attended per 100 women initiating breast feeding per year (fig 4). Individual locality breastfeeding outcomes could not be explained by group attendance or the number of group meetings held.

Of 1310 intervention group attenders, 1231 (94\%) completed questionnaires; 74 attended from nonparticipating general practices, and 138 attended from control locality general practices. Of these 138 women, $132(96 \%)$ attended the only group held in a locality maternity unit, which had been running for more than 10 years. Group attenders were predominantly white (1196/1207; 99\%), and about half had left full time education aged 18 or below $(635 / 1224 ; 52 \%)$. Their median age was 32 (28-35), two years older than all locality women initiating breast feeding $(\mathrm{P}<0.001)$. Women first attended a group a median of 36 (22-81) days after giving birth. Group diaries recorded 284 group facilitators; 183 (64\%) completed questionnaires, and 32 facilitated at more than one group. The median number of facilitators present at any one group meeting was 1.6. Facilitators were health visitors $(46 \%)$, midwives (16\%), students (13\%), and lay volunteers $(9 \%)$. Their median age was $42(36-47)$, and $78 \%$ had personally breast fed.

\section{Costs and benefits}

The main cost of breastfeeding groups relates to staff time, which varied considerably between groups owing to differences in the number of staff attending and the length of time of group meetings. The average cost per locality per year was approximately $£ 13400$ (€14 410; $\$ 20144)$, including travel time (2005/6 prices). The cost equates to $£ 143$ for each woman attending $(n=1310)$. Each woman attended a median of four times. Based on the median, the cost per attendance would be $£ 36$, which is similar to the cost of a home visit by a health visitor (£31). ${ }^{31}$ Other minor costs were incurred for premises, equipment, and refreshments. Completed costs and benefits questionnaires were returned by 175 women attending intervention breastfeeding groups (a minimum response rate of 53\%) and by 156 women attending control postnatal groups (a minimum response rate of $27 \%$ ). Response rate denominators were uncertain, as not all unused questionnaires were returned. The income of women attending breastfeeding groups was significantly higher than those attending postnatal groups $(\mathrm{P}=0.02)$ (table 4). Little difference existed in time and travel costs between attending a breastfeeding group or a postnatal group; most women travelled less than 5 miles, and most journeys took less than 10 minutes. Mean willingness to pay to attend the groups was $£ 2.42$ for the intervention group and $£ 2.54$ for the control group; the difference between the groups was not statistically significant. This figure should be interpreted carefully, as women had also incurred time and travel costs to attend the groups and $83.8 \%$ of respondents in the intervention groups stated that the benefits to them of attending the group were greater than the costs to them; only $2.7 \%$ stated that the costs were greater than the benefits.

\section{DISCUSSION}

This study shows that a policy to provide breastfeeding groups has no impact on rates of breast feeding in the first six to eight weeks after birth and highlights several challenges in the pragmatic implementation of health

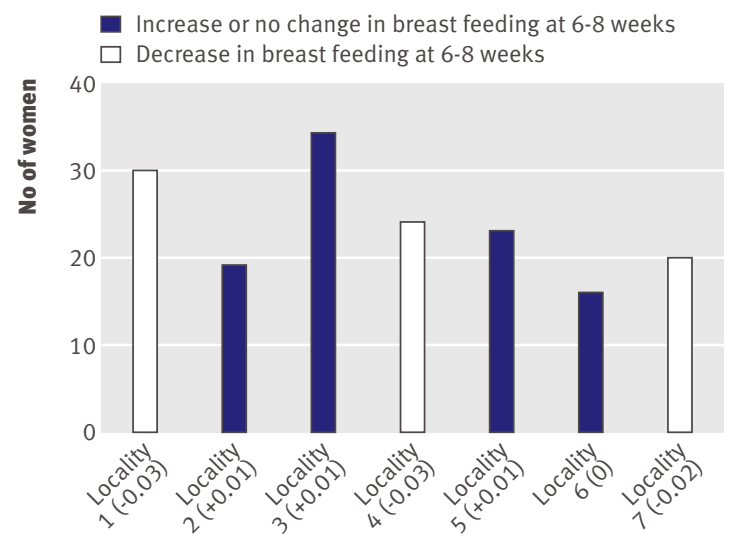

Fig $4 \mid$ Women attending breastfeeding groups (pregnant or breastfeeding) per 100 locality women initiating breast feeding per year. Median=23 (interquartile range 19-30). Change in breast feeding at 6-8 weeks from two years before intervention and two intervention years shown in brackets below locality 
promotion initiatives. Our intervention may not have worked because insufficient women attended groups in pregnancy (the intended behaviour) and before six to eight weeks after birth to influence population breastfeeding rates. Groups attract older and higher income women who are more likely to continue breast feeding anyway, ${ }^{4}$ and social support levels were generally high. A trial of groups for the prevention of postnatal depression reports similar findings. ${ }^{32}$

The embedded mixed method case study design provides insight into why the preliminary study was effective and the trial was not. ${ }^{13}$ In the preliminary study, attendance by pregnant women was six times higher and attendance by any woman (pregnant or breast feeding) was four times higher, more midwives facilitated groups, and three out of five groups took place in community maternity units compared with only one (the best attended) of 27 groups in the trial. More centralised maternity services, reorganisation, and workforce pressures contributed to these differences. ${ }^{33}$ The preliminary study used action research methods, ${ }^{16}$ compared with a distant research team running a trial, and partnership working between midwives, health visitors, and women was less evident in the trial. Involvement of midwives is crucial to recruit pregnant women to groups, as health visitors' first contact is usually 10-14 days after birth, when 17\% of women have stopped breast feeding. ${ }^{4}$ The discontinuity of professional care during women's breastfeeding journey from pregnancy to weaning warrants review, as maternity care has changed considerably with shorter hospital stays.

Table $4 \mid$ Comparison of income, travel times, and car journey distances for breastfeeding (intervention) and postnatal (control) groups. Values are numbers (percentages)

Breastfeeding groups $(n=175)$

Postnatal groups $(n=156)$

Income*

\begin{tabular}{lcc}
\hline$£ 10000$ & $7(4)$ & $16(10)$ \\
\hline$£ 10000-£ 19000$ & $17(10)$ & $23(15)$ \\
\hline $20000-£ 29000$ & $29(17)$ & $31(20)$ \\
\hline$£ 30000-£ 39000$ & $37(21)$ & $26(17)$ \\
\hline$£ 40000-£ 49000$ & $35(20)$ & $29(19)$ \\
\hline$\geq £ 50000$ & $49(28)$ & $6(4)$ \\
\hline Missing & $1(1)$ & $60(38)$ \\
\hline Travel time (all modes) (minutes) & & $59(38)$ \\
\hline$\langle 5$ & $61(35)$ & $31(20)$ \\
\hline $5-10$ & $64(37)$ & $4(3)$ \\
\hline $10-20$ & $40(23)$ & $2(1)$ \\
\hline $20-30$ & $9(5)$ & $(\mathrm{n}=94)$ \\
\hline 30 & $1(1)$ & $16(17)$ \\
\hline Travel distance (car journeys) (miles) & $(\mathrm{n}=106)$ & $21(22)$ \\
\hline$\langle 1$ & $25(24)$ & $18(19)$ \\
\hline $1-2$ & $29(27)$ & $13(14)$ \\
\hline $2-3$ & $13(12)$ & $12(13)$ \\
\hline $3-4$ & $20(19)$ & $14(15)$ \\
\hline $4-5$ & $9(8)$ & $10(9)$ \\
\hline 5 & & \\
\hline Significant difference between groups (P=0.023) & & \\
\hline
\end{tabular}

page 8 of 10

\section{Strengths and limitations}

Few trials of a public health policy in primary care have been done. This trial illustrates the value of routinely collected data on infant feeding and the challenges of systematically collecting non-routine data at population level. Unfortunately, national policy changes led to abandonment of collection of 8-9 month routine breastfeeding data after the first trial quarter, despite the fact that the trial was government funded. Trials of perinatal education, support, or behaviour modification interventions in group settings often use selected samples, in highly controlled environments with experts delivering the intervention, ${ }^{6734}$ which raises questions about generalisability. A strength of this pragmatic trial is that it was designed to take place in a routine service setting, delivered by front line health professionals.

Participating localities were more deprived and had lower baseline breastfeeding rates than the Scottish average. However, the large numbers of women included may have inflated the importance of the small changes in maternal age and deprivation seen. Our findings may not be generalisable to less deprived populations or countries with higher breastfeeding rates, where breast feeding is more socially acceptable and sustaining groups might be easier. Qualitative case study data (to be reported separately) suggest that operational factors, particularly socio-geographic characteristics of localities including deprivation, staff resources, the amount of organisational change, and the style of management and leadership, all affected implementation of the trial and seem to explain why breastfeeding rates declined in three intervention localities.

During the intervention, more babies were born in hospitals that achieved the baby-friendly hospital initiative award or the certificate of commitment in control localities, and initiation of breast feeding increased in these localities. In retrospect, some people might argue that we could have matched by babyfriendly hospital status, given the evidence that it increases duration of breast feeding. ${ }^{11}$ However, our data support the view that in the UK the initiative does not have an effect beyond initiation of breast feeding and that earlier research showing an increase in breast feeding at 5-7 days might depend on the amount of time since the award was achieved. ${ }^{1235}$ The changes in status therefore seem unlikely to have outweighed the effects of the intervention, but we cannot rule this out.

Attending groups and developing social networks may have other short term and long term benefits that we did not measure. Few conclusions can be drawn from our questionnaire derived secondary outcomes owing to the low response rate. Reported attendance rates were higher at general antenatal groups than at breastfeeding groups in both trial arms, and we would recommend review of the current practice of providing separate antenatal breastfeeding education. 


\section{WHAT IS ALREADY KNOWN ON THIS TOPIC}

Additional professional and lay support increases the duration and exclusivity of breast feeding

Little is known about the effectiveness of a group setting for breastfeeding interventions

Older and higher income women are more likely to initiate breast feeding

\section{WHAT THIS STUDY ADDS}

Breastfeeding support groups, facilitated by health professionals, for pregnant and breastfeeding women did not improve breastfeeding rates in the first six to eight weeks after birth

Of women initiating breast feeding, older women were more likely to attend groups; women attending breastfeeding groups had a higher income than those attending postnatal groups

The costs of providing groups are similar to the costs of home visits by health visitors

\section{Conclusion}

If the NHS aims to increase breastfeeding rates, a policy to provide breastfeeding groups, despite being a low cost option that women attending find helpful, is nevertheless ineffective in the current organisational context. Resources may be better directed to the first two weeks after birth, when the highest proportion of women stop breast feeding.

We thank all the managers, health professionals, volunteers, and women who participated in this trial and made it possible. We thank Lee Dowie for trial administration, Fiona Ryan for secretarial support, Roisin Pill (Cardiff University) for qualitative research consultancy, Marion Campbell (University of Aberdeen) for statistical consultancy, Mary Whitmore for training in group facilitation skills, and the Scottish National Neonatal Screening Laboratory, Yorkhill, Glasgow for providing breastfeeding data at 5-7 days gathered on Guthrie cards.

Contributors: PH had the idea for the study. PH, JB, DJG, AL, DT, J Mollison (University of Oxford), and R McInnes (University of Stirling) designed the study. PH and JB coordinated the trial. Quantitative data collection and intervention implementation were overseen by principal investigators (Anne Burns, David Cairns, Angie Docherty, Karen McVittie, Belinda Morgan, Diana Morgan, Marella O'Neill) and local investigators (Jacqueline Allison, Wilma Barnes, Karen Callery, Anne Docherty, Catriona Dreghorn, Gillian Graham, Gina Graham, Liz Greene, Janice Janeczko, Zea Kennedy, Catriona MacLean, Debby Millar, Rosemary Mould, Margaret Pieroni, Andrina Reid, Joan Syme, Ruth Walsh, Emily Whitelaw). All principal and local investigators were employed by NHS Scotland. AL collected and analysed health economic data, with assistance from $\mathrm{L}$ Ternent. PH and JB collected and analysed qualitative data. J Chalmers and C Nolan (Information and Statistics Division, Scottish Government) provided Child Health Surveillance Programme data. DT provided and managed Guthrie data. GJP led the statistical analyses. K Harrild and O Say helped with data management. $\mathrm{PH}$ is the guarantor.

Funding: The Chief Scientist's Office of the Scottish Government Health Directorate provided funding through a research grant (CZH/4/156). PH was funded through a primary care research career award, and the Health Economics Research Unit, University of Aberdeen received core funding. The funding body had no role in the study design, data collection, analysis, or writing of reports; it received interim progress reports at six and 18 months and a final report after three years.

Competing interests: None declared.

Ethical approval: The Metropolitan Multi-centre Research Ethics Committee approved the study.

Provenance and peer review: Not commissioned; externally peer reviewed.

1 Ip S, Cheung M, Raman G, Chew P, Magula N, DeVine D, et al. Breastfeeding and maternal and infant health outcomes in developed countries. Rockville, MD: Agency for Healthcare Research and Quality, 2007. (Evidence report/technology assessment report No 153.)

2 Horta BL, Bahl R, Martines JC, Victora CG. Evidence of the long-term effects of breastfeeding. Geneva: WHO, 2007.
3 WHO. Global strategy for infant and young child feeding. 2008. www. who.int/child_adolescent_health/topics/prevention_care/child/ nutrition/global/en/.

4 Bolling K, Grant K, Hamlyn B, Thornton A. Infant feeding survey 2005. London: NHS Information Centre, 2007.

5 Dyson L, McCormick F, Renfrew MJ. Interventions for promoting the initiation of breastfeeding. Cochrane Database Syst Rev 2005;(2):CDCD001688.

6 Britton C, McCormick FM, Renfrew MJ, Wade A, King SE. Support for breastfeeding mothers. Cochrane Database Syst Rev 2007;(1):CD001141.

7 Gagnon AJ. Individual or group antenatal education for childbirth/ parenthood, or both. Cochrane Database Syst Rev 2007;(3):CD002869.

8 Hannula L, Kaunonen M, Tarkka M. A systematic review of professional support interventions for breastfeeding. J Clin Nurs 2008;17:1132-43.

9 WHO. Baby-friendly hospital initiative. 2008. www.who.int/nutrition/ topics/bfhi/en/.

10 Demott K, Bick D, Norman R, Ritchie G, Turnbull N, Adams C, et al. Routine postnatal care of women and their babies. London: National Collaborating Centre for Primary Care and Royal College of General Practitioners, 2006.

11 Kramer MS, Chalmers B, Hodnett ED, Sevkovskaya Z, Dzikovich I, Shapiro S, et al. Promotion of Breastfeeding Intervention Trial (PROBIT): a randomized trial in the Republic of Belarus. JAMA 2001;285:413-20.

12 Bartington S, Griffiths LI, Tate AR, Dezateux C the Millennium Cohort Study Child Health Group. Are breastfeeding rates higher among mothers delivering in baby friendly accredited maternity units in the UK? Int J Epidemiol 2006;35:1178-86.

13 Hoddinott $P$, Lee AJ, Pill R. Effectiveness of a breastfeeding peer coaching intervention in rural Scotland. Birth 2006;33:27-36.

14 Hoddinott P, Chalmers M, Pill R. One-to-one or group based pee support for breastfeeding? Women's perceptions of a breastfeeding peer coaching intervention. Birth 2006;33:139-46.

15 Hoddinott P, Pill R, Chalmers M. Health professionals, implementation and outcomes: reflections on a complex intervention to improve breastfeeding rates in primary care. Fam Pract 2007;24:84-91.

16 Waterman $\mathrm{H}$, Tillen D, Dickson R, de Koning K. Action research: a systematic review and guidance for assessment. Health Technol Assess 2001;5(23):iii-157.

17 Hoddinott P, Britten J, Harrild K, Godden DJ. Recruitment issues when primary care population clusters are used in randomised controlled clinical trials: climbing mountains or pushing boulders uphill? Contemp Clin Trials 2007;28:232-41.

18 Perera R, Heneghan C, Yudkin P. Graphical method for depicting randomised trials of complex interventions. BMJ 2007;334:127-9.

19 Bandura A. Self-efficacy: toward a unifying theory of behavioral change. Psychol Rev 1977;84:191-215.

20 Blyth R, Creedy DK, Dennis CL, Moyle W, Pratt J, De Vries SM. Effect of maternal confidence on breastfeeding duration: an application of breastfeeding self-efficacy theory. Birth 2002;29:278-84.

21 HoddinottP, Pill R. Qualitative study of decisions about infant feeding among women in east end of London. BMJ 1999;318:30-4.

22 Dennis CL. Peer support within a health care context: a concept analysis. Int J Nurs Stud 2003;40:321-32.

23 ISD Scotland. Breastfeeding. 2008. www.isdscotland.org/isd/1761. html.

24 Tappin DM, Mackenzie JM, Brown AJ, Girdwood RWA, Britten J, Broadfoot M. Comparison of breastfeeding rates in Scotland in 19901 and 1997-8. BMJ 2001;322:1335-6.

25 Leff EW, Jefferis RN, Gagne MP. The development of the maternal breastfeeding evaluation scale. J Hum Lact 1994;10:105-11.

26 Broadhead WE, Gehlbach SH, De Gruy FV, Kaplan BH. The Duke-UNC functional social support questionnaire. Med Care 1988;26:709-23.

27 Scottish Government Statistics. Scottish household survey. 2008 www.scotland.gov.uk/Topics/Statistics/16002.

28 Scottish Executive. Health for all children 4: guidance on implementation in Scotland. Edinburgh: Scottish Executive, 2005 (available at www.scotland.gov.uk/Resource/Doc/37432/ 0011167.pdf).

29 Scottish Executive. Scottish index of multiple deprivation 2006 general report. Edinburgh: Scottish Executive, 2006 (available at www.scotland.gov.uk/Publications/2006/10/ 13142739/0).

30 NHS Scotland. Community health partnerships. www.show.scot.nhs uk/sehd/chp/index.htm.

31 Curtis L, Netten A. Unit costs of health and social care. Canterbury: Personal Social Services Research Unit, University of Kent, 2006.

32 Reid M, Glazener C, Murray GD, Taylor GS. A two-centred pragmatic randomised controlled trial of two interventions of postnatal support. BJOG 2002;109:1164-70. 
33 McGuire M, Dagge-Bell F, Purton P, Thompson M. Shaping maternity services in Scotland. British Journal of Midwifery 2004;12:674-8.

34 Lumley J, Oliver SS, Chamberlain C, Oakley L. Interventions for promoting smoking cessation during pregnancy. Cochrane Database Syst Rev 2004;4:CD001055.
35 Broadfoot M, Britten J, Tappin DM, MacKenzie JM. The baby friendly hospital initiative and breast feeding rates in Scotland. Arch Dis Child Fetal Neonatal Ed 2005;90:F114-6.

Accepted: 30 September 2008 